\title{
A prospective observational study of drug therapy problems in medical ward of a referral hospital in northeast Ethiopia
}

\author{
Yaschilal Muche Belayneh", Gedefaye Amberbir and Asrat Agalu
}

\begin{abstract}
Background: Drug therapy problem is any undesirable event experienced by a patient during drug therapy that interferes with achieving the desired goals of therapy. Drug therapy problems are common causes of patient morbidity and mortality. There was no study that has been done on drug therapy problems in the study area, Dessie referral hospital, northeast Ethiopia.

Method: A prospective observational study was conducted among hospitalized patients in the medical ward of Dessie referral hospital from March 01 to May 31, 2014. Ethical approval was obtained and informed consent was signed by each study participant before the commencement of the study. All patients admitted to the ward during the study period were included in the study. Data regarding each patient's demographics, medical condition, drug therapy and patient compliance to the drug therapy were collected using pretested checklists, and drug therapy problems were determined based on the standard practice and textbooks. Descriptive statistical analysis was done using SPSS Version 20 Software.
\end{abstract}

Result: A total of 147 patients were included, $75.51 \%$ of whom experienced at least one drug therapy problem. During the 3 month period a total of 159 drug therapy problems were identified of which needs additional drug therapy (35.85\%) was the most common followed by unnecessary drug therapy (30.19\%) and dosage too low (13. 2\%). Antibiotics, 75 (40.32\%) was the most frequent drug class involved in drug therapy problems followed by cardiovascular drugs, 69 (37.1\%) and nonsteroidal anti-inflammatory drugs, 9 (4.84\%). Ceftriaxone (25.81\%) was the most frequent specific drug prone to the drug therapy problems followed by spiranolactone (14.52\%), enalapril (6. 45\%) and furosemide (6.45\%).

Conclusions: Three out of four patients experienced at least one drug therapy problem during their hospital stay in the medical ward, with the most commonly observed DTP being no drug therapy prescribed for a condition requiring drug treatment.

Keywords: Drug therapy problem, Dessie referral hospital, Hospitalized patients, Medical ward

\section{Background}

Drug therapy problem (DTP) is any undesirable event experienced by a patient related to drug therapy which interferes with achieving the desired goals of therapy. DTPs are usually classified as; needs additional drug therapy, unnecessary drug therapy, ineffective drug therapy, dosage too low, dosage too high, adverse drug

\footnotetext{
* Correspondence: yaschilal.muche19@gmail.com

Department of Pharmacy, College of medicine and Health Sciences, Wollo University, P.O. Box 1145, Dessie, Ethiopia
}

reaction (ADR) and noncompliance. They are a major safety issue for hospitalized patients [1-3].

It is estimated that approximately 5 to $10 \%$ of all hospital admissions are drug related, and about $22 \%$ of patients are discharged with DTPs. As many as $28 \%$ of all emergency department visits are drug related $[4,5]$. Common drug therapy problems resulting in emergency department visits are adverse drug reactions, noncompliance, and inappropriate prescribing [4]. Pharmaceutical drugs are associated with fatal adverse drug reactions in $3.1 \%$ of the total hospital admission and in $6.4 \%$ of those

(C) The Author(s). 2018 Open Access This article is distributed under the terms of the Creative Commons Attribution 4.0 International License (http://creativecommons.org/licenses/by/4.0/), which permits unrestricted use, distribution, and 
who die in hospital [6-8]. It has been estimated that 3 to $14 \%$ of total hospital admissions to medical wards are related to ADR which is one of the DTPs. ADR is one of the major challenges in the healthcare system due to increased patient morbidity, mortality, and healthcare costs [9-12].

According to the observational, longitudinal study at School Pharmacy of Newton Paiva University Center in Brazil, 91.7\% of the patients experience at least one DTP during their hospital stay, $46.3 \%$ of patients experience more than three DTPs (ranging from 4 to 12 DRPs), $15.5 \%$ three DTPs and $11.3 \%$ two DTPs [13]. In Jimma University specialized hospital (JUSH) of southwest Ethiopia, unnecessary dug therapy was the most common drug therapy problem identified $(24.2 \%)$ followed by needs additional drug therapy, $22.8 \%$; noncompliance, $19.5 \%$ and dosage too low, $12.1 \%$ [14]. Generally DTPs are among the health care issues resulting in increased costs, morbidity and mortality when sever. To our knowledge, there was no previous study on drug therapy problems in hospitals of northeast Ethiopia particularly Dessie referral hospital. Thus, this study was aimed to determine the frequency of DTPs in the medical ward of Dessie referral hospital, northeast Ethiopia.

\section{Methods}

\section{Study area and period}

A prospective observational study was conducted from March 01, 2014 to May 31, 2014 in the medical ward of Dessie referral Hospital (DRH), located in Dessie town, northeast Ethiopia, $400 \mathrm{~km}$ from Addis Ababa. It is serving Dessie town and the surrounding population of about 7 million. This hospital is the only referral hospital in the northeastern part of Ethiopia. There were 165 health professionals working in the hospital. It has different Wards among which Medical ward is the one giving specialized medical services to the patients. There was no pharmaceutical care service in the hospital till the completion of this study.

\section{Study participants}

A convenience sampling technique was employed to select patients for the study based on a study period. All patients admitted to the medical ward of the hospital during the study period, from March 01 to May 31, 2014, were included in the study. Critically ill patients requiring intensive care unit (ICU) admission and patients who were discharged before the collected data was crosschecked were excluded from the study.

\section{Data collection and identification of drug therapy problems}

Data were collected by trained graduating class clinical pharmacy students using pre-tested data collection checklist. Data were collected from patient cards, medical charts, physicians' ward rounds and the multidisciplinary morning meetings. The following data were recorded for each patient: age, gender, body weight, family and social histories, history of drug allergies, relevant medical and medication history, vital signs, drugs used at admission, drugs started during the hospital stay and at discharge, results of routine laboratory tests and the diagnosed diseases which are important for identification of drug therapy problems. The data collectors were involved in rounds of the medical ward to document each drug therapy, and each patient was assessed for compliance to the prescribed drug therapy using semi-structured interviews. Patient cards were reviewed, and patients were interviewed and followed starting from admission until discharge. Each documented drug therapy was evaluated for the presence of DTP everyday using standard textbooks and guidelines [15-20]. When a DTP was identified, the physicians were informed to resolve the problem for ethical reasons. The reliability and accuracy of each drug therapy problem was assessed by independent clinical pharmacist and physician. Unrealistic DTPs, which were not confirmed by both the pharmacist and physician, were excluded (Fig. 1).

The collected data were cleared and checked every day for completeness and consistency before processing. Data were entered and descriptive statistical analysis was done using SPSS Version 20 Software.

\section{Ethical consideration}

Prior to the study, ethical approval was obtained from the ethical review committee of college of medicine and health sciences, Wollo University. The management of the Hospital was requested for cooperation with a formal letter from Wollo University. Each study participant signed a written consent to participate in the study. During and after the data collection process all patient-related data were kept confidential.

\section{Definition of terms Unnecessary drug therapy}

A DTP that occurs when there is no valid medical indication for the drug at the time, or multiple drug products are used while only single-drug therapy is appropriate, or the condition is best treated with nondrug therapy, or the medical problem is caused by drug abuse, alcohol use, or smoking $[1,21]$.

\section{Needs additional drug therapy}

A DTP that occurs when there is a medical condition needing new drug therapy, or preventive therapy is needed to reduce the risk of developing a new condition, or a medical condition requires combination therapy for better efficacy $[1,21]$. 


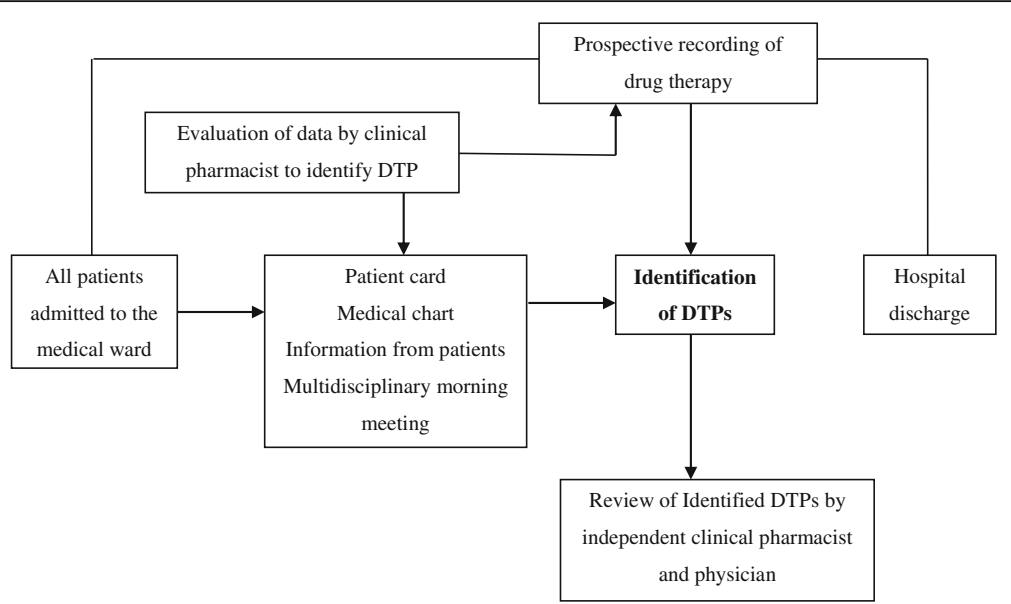

Fig. 1 Flow chart for the prospective study of DTPs at the medical ward of DRH, March 01 to May 31, 2014

\section{Ineffective drug therapy}

The drug is not the most effective for the medical problem, or the drug product is not effective for the medical condition, or the condition is refractory to the drug product being used, or the dosage form is inappropriate $[1,21]$.

\section{Dosage too low}

It is a DTP that occurs when the dose is too low to produce the desired outcome, or the dosage interval is too infrequent, or a drug interaction reduces the amount of active drug available, or the duration of therapy is too short $[1,21]$.

\section{Dosage too high}

The dose is too high or the dosing frequency is too short or the duration of therapy is too long for the patient, or a drug interaction causes a toxic reaction to the drug product, or the dose was administered too rapidly $[1,21]$.

\section{Adverse drug reaction}

The drug product causes an undesirable reaction that is not dose-related, or a safer drug is needed because of patient risk factors, or a drug interaction causes an undesirable reaction that is not dose-related, or the regimen was administered or changed too rapidly [1].

\section{Noncompliance}

A DTP that occurs when the patient doesn't understand the instructions, or the patient prefers not to take or forgets to take the medication, or the cost of drug product is not affordable for the patient, or the patient cannot swallow or self-administer the medication properly, or the drug product is not available for the patient $[1,21]$.

\section{Results}

Socio-demographic variables

One hundred forty seven (147) patients (age range, 18 to 74 years) were included in the 3 month study period; among which 87 (59.18\%) were women. One hundred fourteen (114) of the patients (77.55\%) were in the age range of $<50$ years, $18(12.24 \%)$ participants were in the age range of 50-64 and the rest $15(10.2 \%)$ patients were in the age range of $>64$ years. Of the total patients 90 (61.22\%) were Muslims, 51 (34.69\%) were orthodox Christians, $6(4.08 \%)$ were protestant Christians. The majority of the analyzed patients were married, 99 (67.34\%) (Table 1).

Table 1 Socio-demographic characteristics of the patients in the medical ward of DRH, March 01 to May 31, $2014(N=147)$

\begin{tabular}{lll}
\hline Variable & & $N(\%)$ \\
\hline Sex & Female & $87(59.18)$ \\
Age & $<50$ & $60(40.82)$ \\
& $50-64$ & $114(77.55)$ \\
& $>64$ & $18(12.24)$ \\
Education Level & Illiterate & $15(10.2)$ \\
& Primary school completed & $69(46.94)$ \\
& Secondary school completed & $24(16.32)$ \\
& Diploma & $39(26.53)$ \\
& Degree and above & $12(8.16)$ \\
Religion & Orthodox Christian & $3(2.04)$ \\
& Muslim & $51(34.69)$ \\
& Protestant & $90(61.22)$ \\
Marital status & Single & $6(4.08)$ \\
& Married & $24(16.32)$ \\
& Widow & $99(67.34)$ \\
& Divorced & $3(2.04)$ \\
& & $21(14.28)$ \\
\hline
\end{tabular}




\section{Drug therapy problems}

All of the included patients had, at least, one disease with a diagnosis done by a physician. A total of 296 diseases were reported. Of the total patients 69 (46.94\%) reported one disease, $44(29.93 \%)$ reported 2 diseases, 15 (10.2\%) reported 3 diseases, $7(4.76 \%)$ reported 4 diseases, 7 (4.76\%) reported 5 disease, 4 patients $(2.72 \%)$ reported 6 disease and the remaining 1 patient (0.07\%) reported 7 diseases. The most commonly reported diseases were cardiovascular disorders, 56 (18.92\%) followed by GI disorders, 52 (17.57\%); RTI, 48 (16.22\%); CNS infections, $32(10.81 \%)$ and hematologic disorders, 32 (10.81\%) (Table 2).

The average hospital stay of the patients in the medical ward of Dessie referral hospital was 6.2 days (range $=2$ to 17 days). A total of 657 medications were prescribed for the studied patients during their hospital stay. The average utilization was 4.47 medications per patient (range $=2$ to 9 ). The most commonly utilized medications were Antibiotics corresponding to 192 (29.22\%) mentions (Table 3).

A total of 159 DTPs were identified during the 3 month period involving 111 (75.51\%) patients (69 females, 42 males) out of the 147 patients. An average of 1.08 drug therapy problems were recorded per patient, and an average of 0.48 DTPs were identified per medication order during the study period. The average incidence of DTPs was found to be 0.01 /patient-day. Of the total patients, 69 (46.94\%) had one DTP, 36 (24.49\%) had two DTPs, 6 (4.08\%) had 3 DTPs, and the remaining 36 (24.49\%) had no identified DTPs.

Table 2 Frequency of diseases in the medical ward of DRH, March 01 to May 31, 2014

\begin{tabular}{ll}
\hline Diagnosed diseases & $\mathrm{N}(\%)$ \\
\hline Cardiovascular disorders & $56(18.92)$ \\
Gl disorders & $52(17.57)$ \\
RTI & $48(16.22)$ \\
CNS infections & $32(10.81)$ \\
Hematologic disorders & $32(10.81)$ \\
Parasitic diseases & $16(5.41)$ \\
Endocrinologic disorders & $16(5.41)$ \\
Renal disorders & $12(4.05)$ \\
Opportunistic infections & $8(2.7)$ \\
RVI & $8(2.7)$ \\
Psychiatric disorders & $8(2.7)$ \\
Rheumatologic disorders & $4(1.35)$ \\
UTI & $4(1.35)$ \\
Total & $296(100)$ \\
\hline
\end{tabular}

Abbreviations: Gl gastrointestinal, RTI respiratory tract infection, CNS central nervous system, $R V I$ retroviral infection, UTI urinary tract infection
Table 3 Utilized medications in the medical ward of DRH, March 01 to May 31, 2014

\begin{tabular}{ll}
\hline Medications & $\mathrm{N}(\%)$ \\
\hline Antibiotics & $192(29.22)$ \\
Diuretics & $132(20.09)$ \\
Iron, Ca++, vitamins, and other supplements & $60(9.13)$ \\
NSAIDs & $45(6.85)$ \\
Antacids and antiulcer & $45(6.85)$ \\
Beta blockers & $21(3.2)$ \\
Antiretroviral drugs & $18(2.74)$ \\
Anti-malaria & $15(2.28)$ \\
Digoxin & $15(2.28)$ \\
Anticoagulants & $12(1.83)$ \\
ACEls & $12(1.83)$ \\
Antifungal & $9(1.37)$ \\
Glucocorticoids & $9(1.37)$ \\
Insulin & $6(0.91)$ \\
calcium channel blockers & $6(0.91)$ \\
Propylthirouracil & $6(0.91)$ \\
Antiepileptic drugs & $6(0.91)$ \\
Antipsychotics & $5(0.76)$ \\
Direct vasodilators & $5(0.76)$ \\
Antihyperlipidemics & $5(0.76)$ \\
Oral hypoglycemic drugs & $4(0.61)$ \\
Antiarrhythmic drugs & $4(0.61)$ \\
Antiplatelates & $4(0.61)$ \\
Antihelmenthics & $3(0.46)$ \\
Others & $18(2.74)$ \\
Total & $657(100)$ \\
\hline acyclovir, Dextrometrophan, levodopa and carbidopa \\
\end{tabular}

Of the 159 DTPs, needs additional drug therapy was the most common drug therapy problem identified accounting, 57 (35.85\%). From the 57 DTPs classified as needs additional drug therapy, 33 (57.89\%) were due to a medical condition indicated the need for initiation of drug therapy and $24(42.11 \%)$ were due to the need for preventive drug therapy to prevent the development of a new medical condition. The second most common DTP was unnecessary drug therapy, 48 (30.19\%). Of the 48 DTPs classified as unnecessary, $39(81.25 \%)$ were due to the absence of valid medical indication at that time and 9 (18.75\%) were due to duplication of therapy. The third most frequently identified drug therapy problem was dosage too low, 21 (13.2\%). Other DTPs identified were ADR, 15 (9.43\%); non compliance, 9 (5.66\%) including the patient had no access to the medication 3 (33.33\%) 
and the patient preferred not to take the medications 6 (66.67\%); dosage too high, 6 (3.77\%) including a drug-drug interaction resulted in a toxic reaction to the drug, 3 (50\%), the duration of drug therapy was too long 3 (50\%); ineffective drug therapy 3 (1.89\%) (Fig. 2).

Analysis of drug classes involved in the drug therapy problems showed that antibiotics, 75 (40.32\%), were the most frequent classes of drugs involved in the DTPs; followed by cardiovascular drugs, 69 (37.1\%) involving diuretics, 40 (21.51\%), ACEIs, 15 (8.06\%), beta blockers, 12 (6.45\%) and digoxin, 3 (1.61\%) (Table 4).

A total of 186 specific medications were involved in the identified drug therapy problems of all types. Ceftriaxone $(25.81 \%)$ was the most frequent drug prone to the DTPs followed by spiranolactone (14.52\%), enalapril (6.45\%) and furosemide (6.45\%) (Table 5).

The most common specific drugs involved in each particular DTP include spiranolactone (19.05\%) as needed additional drug therapy, ceftriaxone $(61.11 \%)$ as unnecessary drug therapy, and spiranolactone (28.57\%) and ceftriaxone $(28.57 \%)$ as dosage too low.

Most of the DTPs (41.5\%) were occurred during the treatment of cardiovascular disorders followed by respiratory tract infection, 33 (20.75\%); GI disorders, 27 (16.98\%); CNS infection, 15 (9.43\%); endocrinology disorders, 6 (3.77\%); hematologic disorders, 6 (3.77\%); RVI, $3(1.89 \%)$ and OI, 3 (1.89\%). Some of the identified drug therapy problems are mentioned below as example (Table 6).

\section{Discussion}

This study has shown that $75.51 \%$ of the studied patients had DTPs. This is comparable to the result of the study in Norway which reported $81 \%$ of the hospitalized patients had DTPs [22]. In this study an average of 1.08 DTPs were recorded per patient. This is also comparable to the result of the study at the medical wards of Grenoble University Hospital in which an average of 1.71 DRPs were identified per patient [23]. But according to a retrospective study in Australia, 4.6 drug therapy

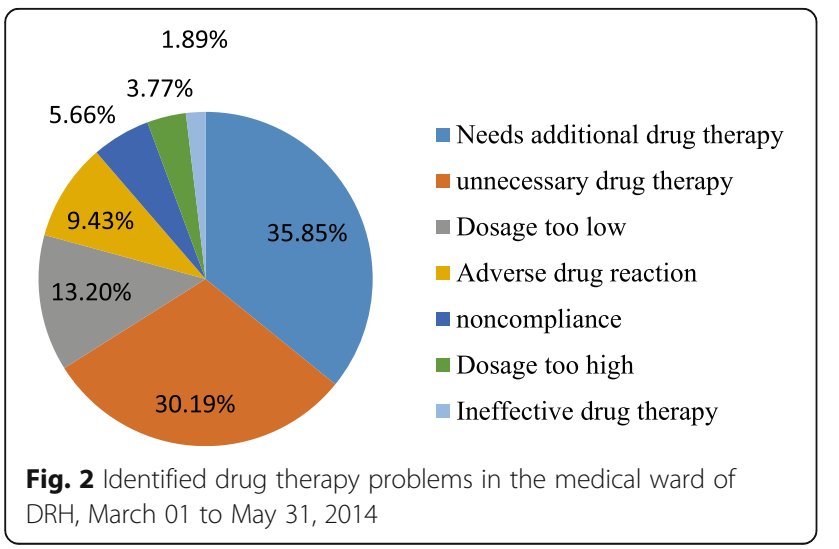

Table 4 Classes of drugs involved in the identified DTPs in the medical ward of DRH, March 01 to May 31, 2014

\begin{tabular}{ll}
\hline Class of drugs & $\mathrm{N}(\%)$ \\
\hline Antibiotics & $75(40.32)$ \\
Diuretics & $40(21.51)$ \\
ACEls & $15(8.06)$ \\
Beta blockers & $12(6.45)$ \\
NSAIDs & $9(4.84)$ \\
Iron, Ca++, vitamins and other supplements & $9(4.84)$ \\
Antihyperlipidemics & $7(3.76)$ \\
Dextromethrophan & $6(3.23)$ \\
Antiretroviral drugs & $4(2.15)$ \\
Antacid and antiulcer & $4(2.15)$ \\
Digoxin & $3(1.61)$ \\
Dextrometrophan & $2(1.06)$ \\
Total & $186(100)$ \\
\hline
\end{tabular}

Abbreviations: $A C E l$ angiotensin converting enzyme inhibitor, NSAID Nonsteroidal anti-inflammatory drug

problems were identified per patient [24]. This is high as compared to the results of our study and the reason may be due to lower number of diagnosed diseases per patient during the study period which can possibly lead to decreased occurrence of DTPs in the medical ward of DRH.

Of the 159 DTPs identified in this study, needs additional drug therapy (35.85\%) was the most common drug therapy problem; followed by unnecessary drug therapy, 30.19\%; and dosage too low, $13.2 \%$. This is comparable to the result of a prospective observational study which was conducted in JUSH in which unnecessary dug therapy was the most common drug therapy problem

Table 5 Specific drugs involved in the drug therapy problems in the medical ward of DRH, March 01 to May 31, 2014

\begin{tabular}{ll}
\hline Specific drug & $\mathrm{N}(\%)$ \\
\hline Ceftriaxone & $48(25.81)$ \\
Spiranolactone & $27(14.52)$ \\
Enalapril & $12(6.45)$ \\
Furosemide & $12(6.45)$ \\
Atenolol & $6(3.22)$ \\
Clarithromycin & $6(3.22)$ \\
Dexamethasone & $6(3.22)$ \\
Iron supplement & $6(3.22)$ \\
Metronidazole & $6(3.22)$ \\
Propranolol & $6(3.22)$ \\
Others & $51(27.42)$ \\
Total & $186(100)$
\end{tabular}

Others: Antibiotics, diuretics, ACEIs, BBs, NSAIDs, Antihyperlipidemics, Digoxin, Antiretroviral drugs, $\mathrm{Ca}++$, vitamins and other supplements 
Table 6 Examples of drug therapy problems in the medical ward of DRH, March 01 to May 31, 2014

\begin{tabular}{ll}
\hline Type of DTP & Examples \\
\hline Needs additional drug therapy & $\begin{array}{l}\text { ACEI was not prescribed for AHA stage C, CHF with no contraindication to the medication. } \\
\text { Propranolol or nadolol was not prescribed for the patient with chronic liver disease and } \\
\text { portal hypertension to prevent variceal bleeding. } \\
\text { Dextrometrophan was prescribed for community acquired pneumonia. } \\
\text { Ceftriaxone was prescribed with fluconazole to treat cryptococcal meningitis. }\end{array}$ \\
Unnecessary drug therapy & $\begin{array}{l}\text { Spiranolactone } 50 \mathrm{mg} \text { PO once daily was prescribed to treat ascites instead of } 100-400 \mathrm{mg} \text { per day. } \\
\text { Ceftriaxone } 1 \mathrm{~g} \mathrm{IV} \mathrm{BID} \mathrm{was} \mathrm{prescribed} \mathrm{to} \mathrm{treat} \mathrm{meningitis} \mathrm{instead} \mathrm{of} 2 \mathrm{~g} \text { BID. }\end{array}$ \\
ADR & $\begin{array}{l}\text { Hypotension was developed due to furosemide } 20 \mathrm{mg} \text { IV BID and spiranolactone } 25 \mathrm{mg} \text { PO once daily. } \\
\text { Noncompliance }\end{array}$ \\
The patient preferred not to take enalapril which was prescribed to treat CHF. & Digoxin $0.25 \mathrm{mg}$ PO once daily was prescribed with Clarithromycin PO BID and then the \\
patient developed cardiac arrhythmia. & Atenolol was prescribed to treat AHA stage C, CHF. \\
Ineffective drug therapy &
\end{tabular}

Abbreviations: $P O$ orally, $I V$ intravenous, BID twice a day, TID three times a day, AHA American heart association, $C H F$ chronic heart failure

identified (24.2\%) followed by needs additional drug therapy, 22.8\%; noncompliance, $19.5 \%$ and dosage too low, $12.1 \%$ [14]. Noncompliance accounts for $5.66 \%$ of the total identified DTPs in our study which was lower compared to the result of the study in the medical ward of JUSH (19.55\%) [14]. This difference might be due to the lower average utilization of medication per patient in the medical ward of DRH which can possibly reduce the occurrence of patient noncompliance.

Antibiotics were the most frequent classes of drugs involved in DTPs, 40.32\%; followed by cardiovascular drugs, 37.1\%; NSAIDs, 4.84\%; iron, $\mathrm{Ca}++$, vitamins and other supplements, $4.84 \%$. This result is similar to the study in the medical wards of Grenoble University Hospital in which cardiovascular drugs were the most frequently implicated (22.2\%), followed by antibiotics/ anti-infective (13.3\%) and analgesics/anti-inflammatory drugs (11.3\%) [23].

According to this study ceftriaxone (25.81\%) was the most frequent specific drug prone to the DTPs followed by spiranolactone $(14.52 \%)$, enalapril $(6.45 \%)$ and Furosemide (6.45\%). This was different from the result of a study in Norway in which the drugs most frequently prone to DTP were Warfarin, digitoxin and prednisolone [22]. This difference might be due to variation in the type of diagnosed diseases and utilized drug therapies.

A number of studies reported that involvement of clinical pharmacists in patient care in the inpatient hospital settings resulted in safer and more effective medication use through identification, resolution and prevention of drug therapy problems [25-31]. As a result, it is recommended to provide pharmaceutical care service at DRH in order to minimize the occurrence of DTPs.

As limitation, this study didn't determine the severity and outcomes of DTPs. Information on past medication history was mainly obtained from the patients or attendants as documentation was scanty. Identification of an ADR was based on clinical assessment made by physicians. Thus the findings might be an underestimate of the number of ADRs. When DTPs were identified, the physicians were informed for ethical reasons and this may have further lead to reduction of subsequent number of DTPs. Critically ill patients requiring ICU admission were excluded from the study which leads to exclusion of complicated cases. Additionally, Convenience sampling restricted to a 3 month study period may lead to failure in capturing probable seasonal variations.

\section{Conclusion}

Three out of four patients experienced at least one drug therapy problem during their hospital stay in the medical ward of Dessie referral hospital, with the most commonly observed DTP being no drug therapy prescribed for a condition requiring drug treatment. Most of the drug therapy problems were occurred during the treatment of cardiovascular disorders, and ceftriaxone was found to be the most frequent drug involved in the DTPs.

\section{Abbreviations}

ACEl: Angiotensin converting enzyme inhibitor; ADR: Adverse drug reaction; CNS: Central nervous system; DRH: Dessie referral hospital; DRP: Drug related problem; DTP: Drug therapy problem; Gl: Gastrointestinal; JUSH: Jimma University specialized hospital; NSAID: Nonsteroidal anti-inflammatory drug; Ol: Opportunistic infection; RTI: Respiratory tract infection; RVI: Retroviral infection

\section{Acknowledgements}

We are thankful to Dessie referral hospital and all the staff members of the medical ward for the permission and continuous assistance to conduct this study. We are also grateful to the study participants for their willingness to take part in the study.

\section{Availability of data and materials}

All the datasets used/or analyzed during the current study are available from the corresponding author on reasonable request.

\section{Authors' contributions}

All authors were involved in the design and write up of the study. YMB and GA conducted the actual study at the hospital and the statistical analysis. All authors read and approved the final draft of the manuscript. 


\section{Authors' information}

YMB is a pharmacologist and lecturer, AA is an assistant professor of clinical pharmacy at department of pharmacy, Wollo University. GA is a pharmacist at a hospital.

\section{Ethics approval and consent to participate}

The study has been approved by the ethical review committee of college of medicine and health sciences, Wollo University. The study participants have signed a written consent to participate in the study.

\section{Consent for publication}

Not applicable.

\section{Competing interests}

All authors declare that they have no competing interests.

\section{Publisher's Note}

Springer Nature remains neutral with regard to jurisdictional claims in published maps and institutional affiliations.

Received: 25 October 2017 Accepted: 8 October 2018

\section{Published online: 22 October 2018}

\section{References}

1. Schwinghammer TL. Pharmacotherapy case book: A patient focused approach. 8th ed; McGraw-Hill Professional Publishing. 2011. p. 23-4.

2. Lampert $\mathrm{M}$, et al. Drug-related problems: evaluation of a classification system in the daily practice of a Swiss university hospital. Pharm World Sci. 2008;30:768-76.

3. Blix $\mathrm{H}$, et al. The majority of patients have drug-related problems: results from a prospective study in general hospitals. Eur J Clin Pharmacol. 2004;60: 651-8.

4. Zed P. Drug-related visits to the emergency department. J Pharm Pract. 2005;18(5):329-35

5. Lopez A, et al. Drug-related problems at discharge programme consultants. Int J Pharm Pract. 2010;18:297-304.

6. Blix $\mathrm{H}$, et al. Characteristics of drug-related problems discussed by hospital pharmacists in multidisciplinary teams. Pharm World Sci. 2006;28:152-8.

7. Viktil $K$, et al. Polypharmacy as commonly defined is an indicator of limited value in the assessment of drug-related problems. Br I Clin Pharmacol. 2006;63(2):187-95.

8. Jonsson AK. Drug-related morbidity and mortality: Pharmacoepidemiological aspects, vol. 25. Sweeden: Linkoping University; 2007.

9. Lagnaoui R, Moore N, Fach J, Longy-Boursier M, Begaud B. Adverse drug reactions in a department of systemic diseases-oriented internal medicine: prevalence, incidence, direct costs and avoidability. Eur J Clin Pharmacol. 2000:56(2):181-6.

10. Dormann H, Neubert A, Criegee-Rieck M, Egger T, Radespiel-Troger M, AzazLivshits $\mathrm{T}$, et al. Readmissions and adverse drug reactions in internal medicine: the economic impact. J Intern Med. 2004;255(6):653-63.

11. Hallas J, Gram LF, Grodum E, Damsbo N, Brosen K, Haghfelt T, et al. Drug related admissions to medical wards: a population based survey. $\mathrm{Br} J \mathrm{Clin}$ Pharmacol. 1992;33(1):61-8.

12. Mehta U, Durrheim DN, Blockman M, Kredo T, Gounden R, Barnes Kl. Adverse drug reactions in adult medical inpatients in a south African hospital serving a community with a high HIV/AIDS prevalence: prospective observational study. Br J Clin Pharmacol. 2008;65(3):396-406.

13. Nascimento Y, Carvalho W, Acurcio F. Drug-related problems observed in a pharmaceutical care service, Belo Horizonte, Brazil. Braz J Pharm Sci. 2009; 45(2):321-30.

14. Mekonnen AB, Yesuf EA, Odegard PS, Wega SS. Implementing ward based clinical pharmacy services in an Ethiopian University Hospital. Pharmacy practice. 2013;11(1):51.

15. Dipiro JT, Talbert RL, Yee GC, et al. Pharmacotherapy: a pathophysiologic approach. 7th ed. New York: McGraw-Hill, Medical Publishing Division; 2008

16. Fauci AS, Kasper DL, Longo DL, et al. Harrison's principles of internal medicine. 17th ed. New York: McGraw-Hill; 2008.

17. Koda-Kimble MA, Young LY, Alldredge BA, et al. Applied therapeutics: the clinical use of drugs. 9th ed. Philadelphia, PA: Lippincott Williams and Wilkins; 2009.
18. Federal Ministry of Health, Ethiopia. Guidelines for management of opportunistic infections and antiretroviral treatment in adolescents and adults in Ethiopia. Ministry of health, Ethiopia. 2007. p. 94.

19. Drug Administration and Control Authority of Ethiopia. Standard treatment guidelines for general hospitals, second edition. Drug Administration and Control Authority of Ethiopia. 2010. p. 464.

20. Baxter K. Stockley's drug interactions pocket Companion. 1st ed. London, UK: Pharmaceutical Press; 2011.

21. Cipolle RJ, Strand LM, Morley PC. Pharmaceutical care practice: a clinician's guide. 2nd ed. New York: McGraw-Hill; 2004. p. 178-9.

22. Blix HS. Drug-related problems in hospitalized patients: Unipub AS. University of Oslo Library. 2007. p. 36-7.

23. Bedouch P, Allenet B, Grass A, Labarere J, Brudieu E, Bosson JL, Calop J. Drug-related problems in medical wards with a computerized physician order entry system. J clin pharm ther. 2009:34(2):187-95.

24. Stafford A, Tenni P, Peterson G, Jackson S, Hejlesen A, Villesen C, Rasmussen M. Drug-related problems identified in medication reviews by Australian pharmacists. Pharm World Sci. 2009;31:216-23.

25. Connor SE, Snyder ME, Snyder ZJ, Steinmetzpater K. Provision of clinical pharmacy services in two safety net provider settings. Pharm Pract. 2009; 7(2):94-9.

26. Altavela $\mathrm{J}$, Jones $M K$, Ritter M. A prospective trial of a clinical pharmacy intervention in a primary care practice in a capitated payment system. J Manag Care Pharm. 2008;14(9):831-43.

27. Stuchbery P, Kong DCM, DeSantis GN, Lo SK. Identification by observation of clinical pharmacists' activities in a hospital inpatient setting. Pharm Pract. 2007;5(1):10-6.

28. Veggeland $\mathrm{T}, \mathrm{Dyb} \mathrm{S}$. The contribution of a clinical pharmacist to the improvement of medication at a geriatric hospital unit in Norway. Pharm Pract. 2008;6(1):20-4

29. Struck P, Pedersen KH, Moodley P, Rasmussen M. A pilot study of pharmacist-initiated interventions in drug therapy in an Australian pediatric hospital. EJHP Sci. 2007;13(4):105-12.

30. Lipton HL, Bird JA. The impact of clinical pharmacists' consultations on geriatric patients' compliance and medical care use: a randomized controlled trial. Gerontologist. 1994;34(3):307-15.

31. Hanlon JT, Weinberger M, Samsa GP, Schmader KE, Uttech KM, Lewis IK, Cowper PA, Landsman PB, Cohen HJ, Feussner JR. A randomized, controlled trial of a clinical pharmacist intervention to improve inappropriate prescribing in elderly outpatients with polypharmacy. Am J Med. 1996; 100(4):428-37.

Ready to submit your research? Choose BMC and benefit from

- fast, convenient online submission

- thorough peer review by experienced researchers in your field

- rapid publication on acceptance

- support for research data, including large and complex data types

- gold Open Access which fosters wider collaboration and increased citations

- maximum visibility for your research: over $100 \mathrm{M}$ website views per year

At BMC, research is always in progress.

Learn more biomedcentral.com/submissions 